\title{
Enunciación
}

http://revistas.udistrital.edu.co/ojs/index.php/enunc

DOI: http://dx.doi.org/10.14483/udistrital.jour.enunc.2015.2.a07

enunciación

AUTOR INVITADO

\section{La petición de la escritura en los escenarios educativos}

\section{The request for writing in educational settings}

\author{
Carlos Skliar', Daniel Brailovsky²
}

Para citar este artículo: Skliar, C. y Brailovsky, D. (2015). La petición de la escritura en los escenarios educativos. Enunciación, 20(2), pp. 261-270.

\section{INTRODUCCIÓN: PEDIR LA ESCRITURA}

En este texto se intenta indagar sobre los diferentes sentidos del pedido del escribir, acerca del pedir la escritura: solicitar el deseo de escribir, y aspirar entonces a ese deslizamiento cálido que, sin exigirse, se espera, se deja ver, se ampara en el vacío a ser llenado; o pedir una buena idea hecha texto, y constituirse entonces en espectador de las palabras pedidas, en un crítico que aplaude o abuchea, en dominio de lo público representado en la lectura del maestro; o pedir técnicas bien aplicadas, pedir tareas bien hechas, pedir sinceridad a toda costa, pedir que algo nuevo para quien escribe se consolide en el terreno de dominio del que pide.

La cuestión primordial de la educación ha sido, es y seguirá siendo la escritura y la lectura, todo lo que ya sabemos y lo que ignoramos, lo que se da por sentado y lo que nunca se reduce a una lógica previa. Sobre todo, la escritura en medio de la educación, como si fuera evidente que allí debiese estar, como si jamás fuera lo suficientemente obvio como para insistir en que allí permanezca: pedir la escritura, enfatizar la importancia de lo escrito, predicar sin demasiados ejemplos a la vista. La escritura enseñada, privilegiada.

Escribir y leer se han vuelto acciones tan evidentes, que ya parece no haber margen para seguir pensándolas, para volver a pensarlas: didácticas, buenas prácticas, planes nacionales, bibliotecas, cuadernos, pizarras, computadoras, teléfonos celulares, libros, partes de libros, partes de partes de libros, apuntes, párrafos, letreros, mensajes, etc. De pequeñísimos a grandotes. Desde casi el nacimiento hasta la hora de la despedida. Todo parece recubrirse de escritura y de lectura. Y sin embargo: ¿Se trata de un camino que ya ha perdido definitivamente su rumbo o de una forma de comunidad que persiste entre nosotros?

En términos educativos, es difícil, sino imposible, separar cierta moralidad de lo útil, de lo necesario y de lo imprescindible. En términos culturales, también lo es. Quizá se trate de adivinar algo de estos tiempos: discernir entre lo actual, la novedad, lo novedoso y lo contemporáneo. En educación parece que siempre vamos detrás de la novedad y lo novedoso; que no coincidimos en definir lo actual -por lo

1 Doctor en Fonología con estudios de posdoctorado en Educación por la Universidad de Barcelona. Investigador independiente del Conicet e investigador principal de Flacso/Argentina, Área Educación. Director de los cursos de posgrado "Pedagogías de las diferencias " y "Escrituras: Creatividad humana y comunicación". Correo electrónico: skliar@flacso.org.ar

2 Doctor en Educación por la Universidad de San Andrés. Investigador del Área de Educación de Flacso/Argentina, docente y tutor en el curso de posgrado "Pedagogías de las diferencias". Correo electrónico: dbrailovsky@flacso.org.ar 
singular, lo contingente, lo rugoso-; y que lo contemporáneo surge solamente como un campo de batallas donde todos acabamos exhaustos.

¿Cómo poner la escritura en medio? ¿Qué escrituras? ¿Solo las aquí y ahora presentes, las breves, las que responden a demandas, las que relacionan la escritura con el trabajo y no con la creación o con la singularidad o con la subjetividad o con la intimidad? ¿El escribir únicamente en medio de las evaluaciones, los diagnósticos? ¿Y todo escribir es equivalente?

Nos parece que educar significa poner en medio, ocupar un entre, hacer cosas, juntos. Y poner la escritura en medio es pensar otra cosa distinta del registro, el archivo, la devolución irrestricta de lo aprendido, o la escritura como un código cerrado para la evaluación. No parece ser interesante sostener apenas una discusión a partir de las imágenes de los copistas medievales, de los escribientes de convento o de los escribidores de ocasión. Hay algo más. ¿Pero qué, exactamente?

\section{LO CONTEMPORÁNEO, LO ACTUAL Y LO NUEVO EN LA ESCRITURA: EL PROBLEMA DEL HUMANISMOY LA "SELECCIÓN" DE LA ESCRITURA}

La escritura ya no es lo que era. Lo que no está ni mal ni bien. Se trata, simplemente, de preguntarse si aún vale la pena darle algunas vueltas a qué era la escritura que ahora no es, a qué es esa escritura que ahora está. Lo que creemos inadecuado es encogerse de hombros en señal de que así son o están las cosas. Lo que nos parece más adecuado es declinar de la idea de que, sin escritura, nos transformamos en animales dóciles, o en humanos aberrantes, incompletos, pues ya sabemos qué provoca la domesticación a través del lenguaje como estandarte.

Pensar en la escritura que acontece en las aulas podría fácilmente situarnos en un tema (el de la alfabetización académica, el de la didáctica de la escritura, el de la evaluación, o alguno otro entre los tantos disponibles en los que la pregunta pudiera caber); pero hemos optado por eludir esta clasificación, e interrogar a la escritura desde nuestra propia escritura.

Y una de las preguntas que vale la pena hacerse, en principio, sería aquella de la relación entre humanismo y escritura. Esa pregunta encuentra aquí -por cierto fuertemente inspirada por algunas ideas del filósofo Peter Sloterdïjk (2000)- dos direcciones o resonancias posibles: 1) la vaga noción de cofradía o de comunidad o de amistad que produciría la escritura; 2) la más sólida afirmación de la escritura como norma. Ambas ideas provienen, en efecto, de la historia del humanismo, pero en diferentes tiempos.

En primer lugar podríamos identificar la historia del humanismo con la historia de la escritura: la escritura como una suerte de carta universal que va pasando de generación en generación gracias a un pacto íntimo y secreto entre emisarios y destinatarios, originales y copias, un vínculo férreo para poder ir más lejos, para no encerrarse, para poder realizar travesías propias y ajenas. Una travesía de ese porte suponía y supone tanto al escritor como al lector. Y esa es la principal virtud de una amistad que durará siglos. Hay, en esta apreciación, un eco de aquel Nietzsche (1996) que buscaba transformar el amor al prójimo -ese amor tan inmediato, tan religioso, tan mezquino- en un amor por vidas ajenas, lejanas, desconocidas. Y esa transformación nos era dada gracias a la escritura como invitación a ir más allá de uno mismo, a salirse, a quitarse la propia modorra, una invitación para abandonar el relato repetido, a despojarse de la identidad del uno como único centro de gravedad y como eje absoluto del universo.

La imagen es conocida y aun así no deja de ser curiosa y amable: un fantasma comunitario -escribe Sloterdïjk- está en la base de todos los humanismos, una suerte de sociedad literaria devota e inspirada, en fin, una comunión en armonía. 
Permanezcamos un poco más en esta imagen y encontremos su contracara. Antes, mucho antes de la Ilegada de eso que hoy llamamos -no sin cierta levedad- el Estado, o mejor aún, el Estado nacional, saber leer y escribir supondría:

[...] algo así como ser miembro de una élite envuelta en un halo de misterio. En otro tiempo, los conocimientos de gramática se consideraban en muchos lugares como el emblema por antonomasia de la magia. De hecho ya en el inglés medieval se derivó de la palabra grammar el glamour; a aquel que sabe leer y escribir, también otras cosas imposibles le resultarán sencillas. Los humanizados no son en principio más que la secta de los alfabetizados, y al igual que en otras muchas sectas, también en esta se ponen de manifiesto proyectos expansionistas y universalistas. (Sloterdiijk, 2000, p. 24)

Subrayemos algunas palabras de este fragmento, por ejemplo: élite, misterio, magia, glamour, secta. Es inmediata la sensación de un mundo partido, quebrado o dividido en función o en virtud, o en el privilegio de la escritura y la lectura. Lo que no hace más que devolvernos a la creencia platónica de una sociedad en la cual todos los hombres son animales -lo que no deja de ser cierto-, pero donde algunos crían a los otros y estos otros serán, siempre, los criados. Para decirlo de otra manera: los animales que leen y escriben educan a los animales que no lo hacen.

Por tanto, el humanismo de los siglos XIX y XX se hizo pragmático, el pragmatismo induce a lo programático y esa sociedad sectaria, mágica, creció hasta volverse una norma para la sociedad política. Como lo afirma Sloterdïjk (2000):

A partir de ahí los pueblos se organizaron a modo de asociaciones alfabetizadas de amistad forzosa, unidas bajo juramento a un canon de lectura vinculante en cada espacio nacional. ¿Qué otra cosa son las naciones modernas sino eficaces ficciones de públicos lectores que, a través de unas mismas lecturas, se han convertido en asociaciones de amigos que congenian? (p.27)

Ese humanismo, el de Estado, es el origen de la imposición de la lectura y la escritura obligatoria: los clásicos, el canon, el valor universal de los textos nacionales.

Ya tendríamos a disposición algunos argumentos para desentrañar tanto la vertiginosa actualidad de la escritura como una insistente impotencia. Las ideas del humanismo ya no pueden contra la época actual; no pueden, no tienen lugar, no caben, son anacrónicas. En buena medida porque también la escritura y la lectura se han transformado en mercancías y ya no requieren de lectores o escritores amables o amigos, sino de consumidores.

Todo se ha sobrevalorado: la literatura, los textos y el espíritu nacionales, la escritura, la lectura. El mundo ya no está organizado por una sociedad ilusoria construida epistolarmente. Ya nadie cree en la docilidad o en la domesticación de la lectura, nadie hablaría de las buenas lecturas o de las escrituras correctas. Inclusive decir que algo está bien escrito provoca solo una sorpresa. Creemos necesario no abandonar las preguntas fundamentales que Sloterdïjk (2000) nos deja en su texto:

¿Qué amansará al ser humano, si fracasa el humanismo como escuela de domesticación del hombre? ¿Qué amansará al ser humano, si hasta sus esfuerzos para autodomesticarse a lo único que en realidad y sobre todo le han llevado es a la conquista del poder sobre todo lo existente? ¿Qué amansará al ser humano, si después de todos los experimentos que se han hecho con la educación del género humano, sigue siendo incierto a quién o a qué educa y para qué el educador? ¿O es que la pregunta por el cuidado y el modelado del hombre ya no se 
puede plantear de manera competente en el marco de unas simples teorías de la domesticación y de la educación? (p. 27)

Lo único que podríamos responder a este incesante cuestionamiento del filósofo es, precaria y provisionalmente, lo siguiente: todavía la escritura y la lectura pueden considerarse como potencias educadoras, pero de un modo más modesto de lo que se ha pensado hasta ahora. Y es modesto porque aún en su potencia corre el riesgo de volverse poder, selección, norma.

\section{LA ESCRITURA Y EL ESCRIBIENDO}

La niña mira a su madre mientras lee. La mira y murmura frases para sí misma. Todo está quieto ahora, en suspenso, como si un largo día no fuera otra cosa que un fin de tarde que nunca desaparece. Cuando la madre hace una pausa, la niña se le acerca y pregunta, con voz de secreto: "Mami: ¿qué estás haciendo?". "Leyendo", responde la madre. La niña insiste: “¿Qué es leyendo?". La madre le muestra el libro a la niña y dice: “¿Ves? Aquí hay historias que todavía no conocemos. Hay que buscarlas. Eso es estar leyendo". La niña se queda quieta y mientras acaricia el brazo de su madre, le pregunta: “ $¿$ Pero: leyendo es en las partes blancas o en las partes negras? (Skliar, 2014, p. 75)

Vamos a servirnos de esta pequeña historia, para sugerir, indicar, apuntar una pregunta crucial, aunque parezca mal escrita: ¿Qué es escribiendo? Nótese que se trata de una pregunta del todo diferente a aquella de: ¿Qué es escribir?, y también de aquella de: ¿Qué es la escritura? Sobre esas dos últimas apariencias de la pregunta ya tenemos suficiente información, aún cuando sea ambigua y contradictoria y debamos distinguir, todavía, entre la racionalidad pedagógica y la racionalidad literaria.

Procuremos entonces preguntarnos por la escritura a través de algunas prácticas, pero acentuando ese escribiendo como único tiempo posible, en el instante en que ocurre, en su duración: ¿Qué puede significar escribiendo, qué es estar escribiendo, para estudiantes y profesores, escritores, escribientes, copistas y demás figuras que giran en torno de ella, en medio de prácticas de transmisión de saberes, valores, conocimientos, materias, currículo? Dirigir nuestra mirada no hacía la huella que deja la mano en movimiento, o hacia los trazos de signos, sino a la mano en sí misma, a la voz que se pronuncia para producir su gesto escritural y al encuentro que habilita la soberanía de esa voz.

Cuando la escritura sucede dentro de las aulas, ven la luz unos textos en los que a menudo pesa mucho más el escribiendo, el escribir como acontecimiento del instante, que una producción material. Y tanto es así, que cuando los educadores piden a los estudiantes que escriban (una composición, un análisis crítico, una reseña, una respuesta, una monografía, incluso una experiencia) se disponen enseguida a la expectativa de un escribir, de un momento de intensidad, de un espacio de confirmación de sentidos, tanto o más que de un texto.

No hay nada claro al respecto. Lo que sabemos es que se pide la escritura, que la escritura proviene por lo general de un pedido. Un pedido ya sea para relatar lo propio como para responder por un texto ajeno; un pedido ya sea para comentar o para definir; tanto para elaborar como para puntualizar. El pedido llega bajo la forma de consignas, preguntas, propuestas, mandatos o sugerencias, y activa un movimiento de escritura en los estudiantes. Los lleva a un (a algún) escribiendo.

No puede dejar de sorprendernos, aun en su aparente habitualidad, esa relación entre escritura y petición. Por varios motivos: en principio porque así se sugiere que lo escrito tiene solo un valor de respuesta; enseguida, porque da la sensación de que - de ser en efecto una respuesta, o de tener apenas esa 
propiedad- no sabemos a qué responde con exactitud, ¿a una pregunta escrita, o un texto leído, a un saber entregado, a una información solicitada, a una necesidad de completar una tarde, al puro y fresco deseo de que alguien se exprese con propiedad?; por último: porque si la escritura fuese reducida a un mecanismo de intercambio estrecho, quedaría confinada al ejercicio de su corrección o de su adecuación y, por consiguiente, a la lógica de lo que es apropiado o inapropiado.

La escritura pedida deja un espacio intermedio de espera, y recibe a cambio un texto. Ese espacio intermedio, el escribiendo, razón última tal vez de toda la petición, es el que nos interesa. Vale la pena saber cómo llega a menudo a quedar confinado a cierto lugar pantanoso donde crecen, como malezas descontroladas, las aberraciones: ortográficas, gramaticales, de concordancia, de literalidad, el plagio, los rictus irreflexivos. Las salas de profesores se poblarán entonces de ejemplos escabrosos, de gestos de indignación y risas ante el absurdo, de envíos por correo electrónico donde se hace público, como escarnio, el error ridículo, la escritura desviada y corrupta. Adentrarnos en ese espacio intermedio, el durante de la escritura, de quienes escriben y hacen del escribiendo un terreno nuevo y propio, permite abrir algunas puertas e indagar en las experiencias que dejaron esas huellas. Entre la escritura y el escribiendo está la experiencia, es decir: "[...] lo que nos pone en una situación de novedad ante lo vivido, lo que nos pone a pensar, lo que requiere nueva significación, lo que nos destapa la pregunta por el sentido de las cosas" (Contreras, 2010, p. 63).

Buscar el escribiendo que está, en efecto, escribiendo. No respondiendo, no completando, no cumpliendo. De otro modo, la escritura es petición, sí, pero también es reflejo del dominio o no, de la capacidad o no, de la diversidad o no, de las prácticas de escritura. En este sentido: ¿Cómo valorar lo que se ha pedido? No queda más remedio, pareciera, que someterlo todo a la ecuación de lo mal o bien escrito, de lo correcto o incorrecto: el zoológico de los que cometen errores y la jauría de los correctores. Pero, ¿dónde estaba, dónde había quedado, lo que se ofrece, lo que se da y no tanto lo que se peticiona y evalúa?

La escritura es petición, la escritura es constatación, pero también es la sombra o el contorno o la superficie de aquello que se ha entregado. Esa escritura pedida y evaluada no habla tanto de la escritura en sí como de la enseñanza, lo que hace tomar a este análisis una dirección completamente diferente. Es verdad que se puede comenzar por los textos escritos por los demás: compadecernos, incomodarnos, asustarnos, dar por sentada que así es, irremediablemente, la producción de esta época. Lo que deberíamos hacer, tal vez, es no omitirnos. No omitirnos del punto de partida: el modo en que nos relacionamos nosotros mismos con la lectura y la escritura. Pero, ¿en qué consistiría esa omisión? En verdad son muchas omisiones, ninguna de las cuales debe entenderse como acusación sin motivos: nuestra lectura cada vez más escasa, cada vez menos literaria y más mediática; los pactos cotidianos en torno a la brevedad y la fragmentación o reducción de los textos que se ponen en juego en las prácticas institucionales; el desprecio por la escritura creativa, ensayada, libre de espíritu; la naturalización artificiosa que supone que buscar es ir hacia los motores de búsqueda; el destierro de las bibliotecas en los confines de los espacios escolares; y, lo que es a la vez más decisivo y más trágico, cierta destrucción del pasado.

\section{QUE VALGA LA PENA ESCRIBIR}

Renegamos de los estudiantes porque no escriben, o porque no escriben con sus propias palabras, o porque no se sueltan, porque no escriben de un modo soberano, no tejen su propio discurso o el discurso enhebrado nos resulta incomprensible. Pero, ¿cómo sería posible hacerlo? ¿Qué permitiría a los estudiantes escribir algo que valiera la pena, que les valiera la pena? 
Para comenzar, escribir podría ser narrar experiencias propias, con palabras propias. Tal vez no sean buenos tiempos para ello, es decir, no puede decirse -como se podía, digamos, una década atrás- que la escritura sea el modo evidente para ese propósito. Aquellos que transitamos por la vida académica somos reprimidos fuertemente al escribir nuestras propias experiencias, en lugar de investigar o estudiar la realidad de otros, en nuestras propias palabras; en lugar de adecuarnos a las palabras en boga. El discutible modelo de la escritura academicista se ha instalado vertical y transversalmente en el mundo educativo como si hubiera algún provecho decisivo en ello. Ensayar, narrar o contar no parecen ser registros amigables en los días que corren. Por tanto, no podemos decir que la petición sea razonable o, ni siquiera asequible, cuando la atmósfera en la que se espera que algo ocurra con la escritura y con la lectura se ha vuelto al menos turbia o, directamente, asfixiante.

Si no se trata solo de escribir lo que nos pasa con nuestras propias palabras, habrá que ir en la búsqueda de otras experiencias y de otras palabras. Se dirá que eso es literatura. Y responderemos que sí, sin dudas. Pero no solo.

En la petición por escribir no caben muchas más opciones: o se trata de un pedido arraigado en tradiciones y racionalidades pedagógicas o, por clara oposición, el pedido es literario, esto es: tocar el límite del lenguaje, tocar sus formas, enclavar la metáfora, dar vueltas sobre los instantes. El resto, substancial por cierto, es la lectura.

Si de verdad buscamos respuestas a la pregunta de por qué escribir, hay un duelo que se debate entre su razón pedagógica y su razón o razones literarias. No basta con decir que escribir o leer sea importante para el mañana, que escribir o leer sirva para el futuro de trabajo o estudio, que escribir o leer garantice una u otra posición de privilegio, una calificación, una distinción. Escribiendo es en presente, no en futuro.

La consigna reza: "Explica, con tus propias palabras...". El estudiante acusa recibo del pedido, y se dispone a confeccionar un texto. Pero la búsqueda de sus propias palabras, en ese contexto, es algo ambigua. ¿Cuándo son propias las palabras? ¿Cuáles son las palabras apropiadas? La expresión "tus propias palabras" Ileva la cuestión, nuevamente, del terreno de lo escritural al terreno de la enseñanza, pues es un dato del pedido más que de la escritura. Y pensando en las energías enseñantes del maestro, podríamos creer también que pedir "tus propias palabras" es un Ilamado a alguna forma de autenticidad y compromiso con lo escrito, es una expresión de deseos del enseñante, de que entre los estudiantes y sus textos tenga lugar algún tipo de intensidad que permita un escribiendo intenso. Podría llegar a ser, bien visto, un modo de ofrecerles a los estudiantes buenas razones para escribir.

Hagamos pues un ejercicio en la búsqueda de algunas pocas respuestas literarias a la pregunta de por qué escribir:

Escribir: para no dejarle el lugar al muerto, para hacer retroceder al olvido, para no dejarse sorprender jamás por el abismo. Para no resignarse ni consolarse nunca, para no volverse nunca hacia la pared en la cama y dormirse como si nada hubiera pasado. (Hélène Cisoux).

Escribo para que el agua envenenada pueda beberse. (Chantal Maillard).

Escribo para que la muerte no tenga la última palabra. (Odysseas Elytis).

Escribo porque estoy muy, muy enfadado con todos ustedes, con todo el mundo. Escribo porque me gusta pasarme el día entero en una habitación escribiendo. Escribo porque solo puedo soportar la realidad si la altero. (Orhan Pamuk).

Escribo para no quedar en medio de mi carne / para que no me tiente el centro / para rodear y resistir / escribo para hacerme a un lado / pero sin alcanzar a desprenderme. (Fabio Morábito). 
¿Es posible, entonces, siquiera imaginar una didáctica o una transmisión de la escritura cuyo epicentro se encuentre inexorablemente en la búsqueda de buenas razones para escribir, esto es, en la muerte, en la última palabra, en el enfado, la dificultad por soportar al mundo, la resistencia, la alteración de lo real, del cuerpo? No es claro; pero es necesario afirmar que justamente de allí proviene la escritura. La escritura que vale la pena. La escritura que, quizá, algún día será leída. Recordada. Y, además, vuelta a trasmitir. A poner en medio. A hacer algo con ella, más allá de la petición y el encogimiento de hombros.

¿Alcanza con pedir a los alumnos que utilicen "sus propias palabras"? Cuando esto se hace, lo que supone apelar a algún tipo de autenticidad, de sello singular en la escritura ¿qué sucede con aquella otra demanda, tal vez más fuerte, de una escritura apropiada, ajustada a la norma, apropiada por estar subordinada a algún orden de lo que es propio en el mundo académico? Vale la pena adentrarnos en este desencuentro entre unos deseos de intensidad que se cobijan a la sombra de esa búsqueda de las propias palabras y esa otra demanda de palabras apropiadas. Lo propio y lo apropiado. Vale la pena, digamos, hundir los pies en el pantano del escribiendo.

Las palabras propias y las apropiadas pueden enemistarse. Un estudiante que iniciaba sus estudios universitarios ha preguntado a su profesor, por ejemplo: "Pero... ¿tenemos que decirlo con nuestras propias palabras o 'en difícil'?". De un lado ha quedado la pretensión de sentido; del otro, la de precisión en el significado. El profesor dudará entonces, y se preguntará: “¿Qué significa realmente que las palabras sean propias? ¿Cuándo es propia la palabra?". Si hablando de las teorías del aprendizaje el estudiante escribe "el nene pequeño aprende tocando todo", ¿haber dicho "nene" (en lugar de sujeto, niño, actor, etc.) es usar las propias palabras? ¿Quién es en todo caso el nene, el niño, el sujeto, el actor? ¿Se puede decir niño, sujeto o actor sin dejar de ser uno mismo? ¿Se puede nombrar a alguien como niño, sujeto o actor y sostenerse en un lenguaje propio? ¿Puede hablarse de alguien sin convertirlo en niño, sujeto o actor, sin borrar su nombre, el espacio de su nombre, su carácter de protagonista de la experiencia? ¿En qué términos es posible decir algo de alguien -no ya con la aspiración de que aquello que se dijo se convierta en máxima universal, sino literalmente, decir algo sobre alguien- sin dejarse decir por los lenguajes convencionales? ¿Puede uno buscar palabras propias que no estén tomadas de un vocabulario estandarizado, y que tampoco se apropien de lo que uno quiere decir?

\section{PALABRAS PROPIAS, PALABRAS APROPIADAS}

La cuestión es, entonces, lograr un encuentro entre aquel lenguaje convencional que las disciplinas proponen y que se presenta como apropiado (ajustado a un orden, subordinado a normas de corrección) y las escrituras singulares de los estudiantes, las que transcurren en la escena vívida de su durante, de su escribiendo. Mientras que el lenguaje académico toma como referencia central unos escenarios teóricos hechos de definiciones, proposiciones enlazadas entre sí, supuestos sobre el mundo acaecido y por acaecer, las escrituras singulares se remiten a la experiencia, y en ella al argumento, al sentido, a las resonancias.

A veces estas corrientes se encuentran de modos sinuosos. Hay lenguajes que, a fuerza de exigírseles propiedad, la procuran tomando de las palabras científicas su modo impostado. Lenguajes que visten con las palabras como corbatas anudadas, que se formalizan y se acartonan, y solo eso. Surge entonces una escritura que despliega, muchas veces de un modo tosco y balbuceado, un vocabulario que, apretado y a los empujones, se acomoda en las oraciones como niños llamados a formar fila para saludar a la bandera. Otras veces las palabras de las teorías son usadas con otros sentidos, y el educador siente que se han malentendido. En ambos casos, los estudiantes son objeto de acusaciones, ya sea por repetir como loros o 
plagiar (en el primer caso), ya sea por no haber comprendido correctamente el uso de los términos (en el segundo). Lo apropiado en la escritura es, evidentemente, susceptible de entenderse de distintas maneras.

Cuando el profesor escucha la pregunta de su alumno (" $i$ Tenemos que decirlo con nuestras propias palabras o 'en difícil'?"), el contraste que se establece es posiblemente entre dos cosas diferentes de lo que él espera. Como docente, aspira a que los estudiantes lleguen a sentir como propias las palabras de un vocabulario que han aprendido, y las usen para construir un argumento. En la pregunta hay, en cambio, un falso dilema entre lo difícil (lo costoso, lo que dará trabajo, lo que se asumirá pretencioso, ceremonioso, acartonado, afectado) y lo vulgar: la lectura más superficial del dilema entre el nene y el niño-sujeto-actor. Donde el docente ve un contraste posible entre una escritura soberana, potente, y una escritura restringida o repetidora, el estudiante intuye otro contraste, entre una escritura con distintos grados de ajuste a un léxico trabajoso y arbitrario, como todos. Un escribiendo doloroso o placentero.

¿Qué debería hacer este maestro? ¿Enseñar a sus estudiantes a escribir como escriben los autores? ¿Apropiarse de ese estilo los convertirá en profesionales que se expresan apropiadamente? ¿O los alienará a un léxico que les impedirá hablar con una voz propia? Regresemos a la hipótesis: tal vez, solo tal vez, sea necesario sumergirse en ese vocabulario, sentir sus vibraciones, hacer sonar sus términos a través de nuestra garganta, de nuestros argumentos, para vivenciar las asfixias, las resonancias, los ecos que traen y no traen, y llegar entonces a (re)construir -una vez más- la propia voz.

Un último ejemplo que muestra otra faceta de este encuentro entre lenguajes propios y apropiados.

El término significativo, surgido de teorías del aprendizaje en los años 1960, específicamente alrededor de la obra de David Ausubel (1963), ha tenido una fuerte acogida en el mundo educativo. Los maestros y formadores, diríamos, se han apropiado de este concepto. Esto ha traído discusiones y críticas: cuando una palabra se convierte en vehículo de ideas compartidas, se hace más o menos inevitable un esfuerzo epistemológico por esclarecer o consensuar sus implicancias. Algunos analizan el modo en que la idea de significativo puede releerse desde un amplio abanico de teorías constructivistas (por ejemplo, Moreira, 1997), y proponen pensar en un aprendizaje crítico o subversivo (por ejemplo Moreira, 2005). Y hay, más habitualmente, una serie de críticas al uso cotidiano del término que, despojado de todo rigor respecto de la definición original, atribuye significatividad a cualquier acontecimiento que despierte alguna forma de disfrute en los alumnos. Se trata, al parecer, de un concepto teórico mal entendido. Hay, sin embargo, algo que se ha acomodado allí y que puede leerse desde las necesidades que instala la experiencia en términos de lenguaje: ¿Será acaso que el disfrute de los alumnos, digamos, necesitaba una palabra que lo nombre, y esta se cayó de las teorías psicológicas para ocupar ese lugar?

\section{CONCLUSIONES}

Hemos dicho más atrás que no son estos buenos tiempos para el lenguaje en general. Una afirmación de esta naturaleza, se dirá, no deviene sino de la nostalgia mítica, de una suerte de desconsuelo por aquellas cosas, aquellos gestos, que han desaparecido o están en vías de desaparecer o se travisten de tal manera que ya no es posible reconocerlos en su rostro conocido. Pero, ¿es una cuestión de época? ¿De su espectacularidad tecnológica? ¿De los dobles nuestros que escriben en las redes? ¿De esta época tan urgenciada de información como también perezosa en su búsqueda?

Pareciera ser que estamos afectados por unos dispositivos de información y de comunicación que entorpecen todo el tiempo lo que quisiéramos decir y decirnos. Las palabras suelen perder su transparencia, su forma perceptiva. Dan vueltas y se revuelcan, se esconden y naufragan: un lenguaje de palabras caídas, pisoteadas, como decía el poeta Juarroz. Y en cierto modo habrá que volver a pensar en un lenguaje 
habitado por dentro y no apenas revestido por fuera. Como la piel, también el lenguaje toma la forma de un latido cardíaco, o de una agitación del respirar, o de un extraño y persistente movimiento; otras veces, se convierte en muralla, en defensa, en contención. Sería todo un gesto no utilizar el lenguaje solo como recubrimiento o encubrimiento de la vida; ser capaces de un lenguaje como desorden, como desobediencia, como una suerte de rebelión frente a un mundo que cada vez nos obliga a hablar más brevemente y más de prisa. El mundo que nos envejece más de prisa. A nosotros y a nuestras palabras.

Pero también habrá que preguntarse por el lenguaje directo, el lenguaje seco, el lenguaje que no dice más que lo que quisiera decir; un lenguaje acaso sin falsedades, sin tecnologías, sin duplicaciones. Un lenguaje sobreviviente, quizá, de nuestro supuesto dominio o de nuestra incapacidad por dominarlo. Un lenguaje cuya voz deriva de lo que nos pasa, como el de los personajes de Claus y Lucas, de Agota Kristof (2007): dos niños que viven en el confín de un pueblo, durante alguna guerra, se ponen a escribir y a tomar decisiones sobre la escritura por primera vez. En determinado momento se preguntan cómo saber si algo de lo que escriben está bien o mal: "Tenemos una regla muy sencilla: la redacción debe ser verdadera. Debemos escribir lo que es, lo que vemos, lo que oímos, lo que hacemos" (p. 63). La crudeza con la que los niños asumen su escritura, su lenguaje, no deja de ser también su desnudez, su transparencia, ese intento para que el lenguaje diga algo, algo que por una vez se sienta verdadero.

Es cierto, una vez más: no son estos buenos tiempos para la complejidad y la ambigüedad del lenguaje. Hay un predomino exagerado de la rapidez y la eficacia en la transmisión y por eso, cada vez más, se van apartando algunas formas de expresión poéticas más rugosas, menos eficaces. Sin embargo, no hay ningún motivo por el cual ligar el lenguaje a la prisa o a la urgencia o a la inmediatez. También el lenguaje puede ser una forma de detención, una pausa que sirva para habitar un tiempo hondo, que nos vincule más a la intensidad que a lo cronológico. No se trata tanto de una cuestión de géneros ni de generaciones, sino de esa tensión -tan viva, tan obsesiva- entre el lenguaje de la información que exige premura y consumidores, y el lenguaje literario que intenta hacer respirar de otra manera a sus lectores.

Las redes sociales han modificado las formas de escribir y comunicarse, y sin duda afectan el acto de leer. Pero por más masivas (y ahora naturales) que se vuelvan esas prácticas, hay algo en el lenguaje que hace que sobreviva a cualquier intento de fijación o moda. Es verdad que uno puede expresarse en 140 caracteres, pero también es cierto que lo puede hacer por millones. No hay ninguna razón para asumir una posición definitiva al respecto, pues es el carácter contemporáneo el que resuelve la convivencia o no entre lo nuevo y lo anterior. Y no hace falta aniquilar formas de escritura y de lectura en nombre de la novedad. Hay un enorme tesoro en el lenguaje y poder encontrarlo es de algún modo una tarea que nos relaciona no solo con el futuro sino también, y sobre todo, con el pasado. El escritor holandés Cees Nooteboom (2007), en su libro Tumbas de poetas y pensadores, sugiere que el pasado es un tesoro que está al alcance de nuestras manos. Se trata de realizar una travesía, de estirarnos hacia un libro, hacia una idea, hacia una palabra, hacia la escritura, hacia otras personas.

Más allá de toda discusión sobre lo nuevo, lo novedoso, lo actual y lo contemporáneo en el lenguaje, aún las preguntas esenciales suponen un temblor siempre presente: ¿Hay algo para decir? ¿Hay algo para escribir? Y en esa tentación al expresionismo y la productividad de la palabra: ¿Hay alguien allí, por dentro de lo que dice, por dentro de lo que escribe? Y aún más: si la cuestión es apenas un problema de quién y qué se emite, ¿hay alguien del otro lado que escuchará y leerá? ¿Alguien que, simplemente, desee una detención, una pausa? 


\section{REFERENCIAS}

Ausubel, D.P. (1963). The psychology of meaningful verbal learning. Nueva York: Grune and Stratton.

Contreras D., J. (2010). Ser y saber en la formación didáctica del profesorado: una visión personal. Reinventar la profesión docente. Nuevas exigencias y escenarios en la era de la información y la incertidumbre. RIFOP, Revista Interuniversitaria de Formación del Profesorado, 68(24), 61-82.

Juarroz, R. (2005). Octava poesía vertical. Buenos Aires: Emecé.

Kristof, A. (2007). Claus y Lucas. Barcelona: El Aleph Editores.

Moreira, M.A. (1997). Aprendizaje significativo: un concepto subyacente. En: M.A. Moreira, M.C. Caballero y M.L. Rodríguez (orgs.). Actas del Encuentro Internacional sobre el Aprendizaje Significativo (pp. 19-44). Burgos: Universidad de Burgos.

Moreira, M. (2005). Aprendizaje significativo crítico. Indivisa, 6, 83-101.

Nietzsche, F. (1996). Humano, demasiado humano. Madrid: Akal.

Nooteboom, C. (2007). Tumbas de poetas y pensadores. Madrid: Ediciones Siruela.

Skliar, C. (2014). Hablar con desconocidos. Barcelona: Editorial Candaya.

Sloterdijk, P. (2000). Normas para el parque humano. Madrid: Siruela. 